OPEN ACCESS

Edited by:

Xiaojuan $\mathrm{Li}$,

Beijing Forestry University, China

Reviewed by:

William Laing,

The New Zealand Institute for Plant and Food Research Ltd., New Zealand

Tse-Min Lee,

National Sun Yat-sen University, Taiwan

*Correspondence:

Zhijin Zhang

zhangzhijin@caas.cn

Yujie Wang

Ikwangyujie@126.com

tThese authors have contributed equally to this work

Specialty section:

This article was submitted to

Plant Abiotic Stress,

a section of the journal

Frontiers in Plant Science

Received: 24 August 2020

Accepted: 17 March 2021

Published: 12 April 2021

Citation:

Xiao M, Li Z, Zhu L, Wang J, Zhang $B$, Zheng $F$, Zhao $B$, Zhang $H$, Wang $Y$ and Zhang $Z$ (2021) The

Multiple Roles of Ascorbate in the Abiotic Stress Response of Plants: Antioxidant, Cofactor, and Regulator.

Front. Plant Sci. 12:598173.

doi: 10.3389/fp/s.2021.598173

\section{The Multiple Roles of Ascorbate in the Abiotic Stress Response of Plants: Antioxidant, Cofactor, and Regulator}

\author{
Minggang Xiao ${ }^{1 t}$, Zixuan $\mathrm{Li}^{2,3 t}$, Li Zhu ${ }^{2,3 t}$, Jiayi Wang ${ }^{2,3}$, Bo Zhang ${ }^{1}$, Fuyu Zheng ${ }^{1}$, \\ Beiping Zhao ${ }^{1}$, Haiwen Zhang ${ }^{2,3}$, Yujie Wang ${ }^{1 *}$ and Zhijin Zhang ${ }^{2,3 *}$
}

${ }^{1}$ Biotechnology Research Institute, Heilongjiang Academy of Agricultural Sciences, Harbin, China, ${ }^{2}$ Biotechnology Research Institute, Chinese Academy of Agricultural Sciences, Beijing, China, ${ }^{3}$ National Key Facility of Crop Gene Resources and Genetic Improvement, Beijing, China

Ascorbate (ASC) plays a critical role in plant stress response. The antioxidant role of ASC has been well-studied, but there are still several confusing questions about the function of ASC in plant abiotic stress response. ASC can scavenge reactive oxygen species (ROS) and should be helpful for plant stress tolerance. But in some cases, increasing ASC content impairs plant abiotic stress tolerance, whereas, inhibiting ASC synthesis or regeneration enhances plant stress tolerance. This confusing phenomenon indicates that ASC may have multiple roles in plant abiotic stress response not just as an antioxidant, though many studies more or less ignored other roles of ASC in plant. In fact, ACS also can act as the cofactor of some enzymes, which are involved in the synthesis, metabolism, and modification of a variety of substances, which has important effects on plant stress response. In addition, ASC can monitor and effectively regulate cell redox status. Therefore, we believe that ASC has atleast triple roles in plant abiotic stress response: as the antioxidant to scavenge accumulated ROS, as the cofactor to involve in plant metabolism, or as the regulator to coordinate the actions of various signal pathways under abiotic stress. The role of ASC in plant abiotic stress response is important and complex. The detail role of ASC in plant abiotic stress response should be analyzed according to specific physiological process in specific organ. In this review, we discuss the versatile roles of ASC in the response of plants to abiotic stresses.

Keywords: ascorbate, abiotic stress, antioxidant, redox signal, phytohormone

\section{INTRODUCTION}

Ascorbate (ASC, known as vitamin C) is an essential micronutrient for humans, and its deficiency can cause several serious diseases, such as scurvy (Baron, 2009; Carpenter, 2012). In plants, it also participates in many physiological processes, such as photosynthesis, cell division, and differentiation, and is crucial for plant growth and development and adaptation to stress (Nickle and Meinke, 1998; de Pinto et al., 1999; de Pinto and De Gara, 2004; 
Sun et al., 2010; Gallie, 2013; Kromdijk et al., 2016; Akram et al., 2017; Foyer et al., 2020).

Ascorbate has a critical role in scavenging reactive oxygen species (ROS) in plants under abiotic stresses, such as highintensity light, high salinity, and drought. These stresses can cause ROS accumulation in plants, which severely damages cell composition and disturbs growth and development (Schieber and Chandel, 2014; You and Chan, 2015; Choudhury et al., 2017). As an antioxidant, ASC can effectively scavenge the accumulated ROS via direct or indirect pathways, and is thus critical for eliminating oxidative damage and enhancing abiotic stress tolerance in plants (Noctor and Foyer, 1998; Akram et al., 2017; Hasanuzzaman et al., 2019; Broad et al., 2020a; Elkelish et al., 2020).

In addition to being an antioxidant, ASC can act as a cofactor of certain oxidases, such as the 2-oxoglutaratedependent dioxygenases (2-ODDs), and participates in the biosynthesis of several phytohormones (Prescott and John, 1996; Arrigoni and De Tullio, 2002; Brisson et al., 2012; Terzi et al., 2015; Mir et al., 2018; Bilska et al., 2019). For example, it is a cofactor of the aminocyclopropane-1-carboxylic acid oxidases (ACOs) and 9-cis-epoxycarotenoid dioxygenases (NCEDs), key enzymes in the biosynthesis of the phytohormones ethylene and abscisic acid (ABA), respectively (Qin and Zeevaart, 1999; Brisson et al., 2012; Houben and Van de Poel, 2019). Phytohormones play important roles in regulating plant responses to abiotic stresses. Hence, ASC participates in plant abiotic stress responses through phytohormone pathways (Chen et al., 2014; Terzi et al., 2015; Bilska et al., 2019; Foyer et al., 2020). Further, as a cofactor, it participates in epigenetic modification, and it regulates plant abiotic stress responses via epigenetic pathways (Chowrasia et al., 2018; Song et al., 2018).

Moreover, ASC has an important effect in cell signaling (Pignocchi and Foyer, 2003; Chen and Gallie, 2004; Foyer et al., 2020). It plays a critical role in maintaining plant extracellular and intracellular redox homeostasis (Noctor and Foyer, 1998; Ding et al., 2020). Plant redox homeostasis is involved in stress signal transmission, and has a profound effect on multiple signaling pathways, such as the ROS, ABA, and auxin signaling pathways (Noctor and Foyer, 1998; Arrigoni and De Tullio, 2002; Pignocchi et al., 2006; LimaSilva et al., 2012; Akram et al., 2017; Zechmann, 2018; Bilska et al., 2019; Foyer et al., 2020). ROS produced by abiotic stress significantly influence the cell redox state. Changes in the cell redox state influence the ability of plants to respond to abiotic stress. Plants can respond rapidly and appropriately to such changes, to better adapt to various abiotic stresses, by monitoring their redox homeostasis (Potters et al., 2010; Sierla et al., 2013; You and Chan, 2015; Choudhury et al., 2017; Foyer, 2018; Waszczak et al., 2018; Farooq et al., 2019; Foyer et al., 2020). Based on its critical role in maintaining plant redox homeostasis, ASC can coordinate the actions of multiple signaling pathways in responses to abiotic stress, by modulating redox signaling (Pignocchi and Foyer, 2003; Akram et al., 2017; Bilska et al., 2019; Foyer et al., 2020). In this review, we will discuss the versatile roles of ASC as an antioxidant, cofactor, and regulator in plant adaptation to abiotic stress.

\section{AS AN ANTIOXIDANT, ASC EFFECTIVELY SCAVENGES ROS AND ENHANCES ABIOTIC STRESS TOLERANCE}

Under abiotic stress, plants produce ROS, such as hydrogen peroxide $\left(\mathrm{H}_{2} \mathrm{O}_{2}\right)$, hypochlorous acid $(\mathrm{HClO})$, ozone $\left(\mathrm{O}_{3}\right)$, singlet oxygen $\left({ }^{1} \mathrm{O}_{2}\right)$, superoxide anion radicals $\left(\mathrm{O}_{2}^{-}\right)$, hydroxyl radicals $\left(\mathrm{OH}^{-}\right)$, perhydroxyl radicals $\left(\mathrm{HO}_{2}{ }^{\circ}\right)$, organic alkoxy $\left(\mathrm{RO}^{*}\right)$, and organic peroxyl radicals (ROO; Dumont and Rivoal, 2019; Dumanović et al., 2020). The accumulated ROS induced by abiotic stress are harmful and must be scavenged (Gill and Tuteja, 2010; You and Chan, 2015; Choudhury et al., 2017; Nadarajah, 2020). By regulating ASC de novo synthesis or recycle regeneration (Figure 1), plants can effectively scavenge many kinds of ROS directly or indirectly, maintaining cellular redox homeostasis (Noctor and Foyer, 1998; Smirnoff and Wheeler, 2000; Gallie, 2013; Akram et al., 2017; Bilska et al., 2019; Hasanuzzaman et al., 2019). ASC is thus critical in eliminating oxidative damage and enhancing abiotic stress tolerance. Photosynthesis can trigger a series of redox reactions that are accompanied by ROS production (Foyer, 2018; Khorobrykh et al., 2020). Excessive accumulation of radical and non-radical ROS in chloroplasts under light stress can damage the plant photosynthetic system. ASC effectively scavenges both types of ROS in chloroplasts, thus helping plants to sustain photosynthesis (Ivanov and Khorobrykh, 2003; Kramarenko et al., 2006; Triantaphylidès et al., 2008; Foyer, 2018; Khorobrykh et al., 2020). The radical ROS $\mathrm{O}_{2}^{-}$ can be reduced to $\mathrm{H}_{2} \mathrm{O}_{2}$ by superoxide dismutase, and $\mathrm{H}_{2} \mathrm{O}_{2}$ can be then eliminated by ASC peroxidases (APXs) using ASC as an electron donor (Talla et al., 2011; Ivanov, 2014). The non-radical ROS ${ }^{1} \mathrm{O}_{2}$ can be directly scavenged by ASC (Kramarenko et al., 2006). In addition, ${ }^{1} \mathrm{O}_{2}$ can oxidize carotenoids and tocopherols; the oxidized tocopherols and carotenoids can then be reduced by ASC, indicating that ASC can scavenge non-radical ROS through directly and indirectly pathways (Veljovic-Jovanovic et al., 2001; Kramarenko et al., 2006; Jahns et al., 2009; Triantaphylidès and Havaux, 2009; Ivanov, 2014). In the Arabidopsis ASC synthesis mutant $v t c 1$, the activity of the ASC synthesis key enzyme GDP-mannose phosphorylase is impaired, causing it to have only about $30 \%$ ASC of that in the wild type; it is therefore, much more prone to photooxidation and photoinhibition under light stress than the wild type (Conklin et al., 1996; Veljovic-Jovanovic et al., 2001; Ivanov, 2014). Similarly, the ASC synthesis mutant $v t c 2$, which has only about $20 \%$ as much ASC as the wild type, exhibits decreased ROS scavenging ability and thus serious oxidative damage under high-intensity light (Müller-Moulé et al., 2004). These results suggest that ASC is crucial in protecting the photosynthetic system from oxidative damage (Noctor and Foyer, 1998; Talla et al., 2011; Ivanov, 2014; Khorobrykh et al., 2020). 


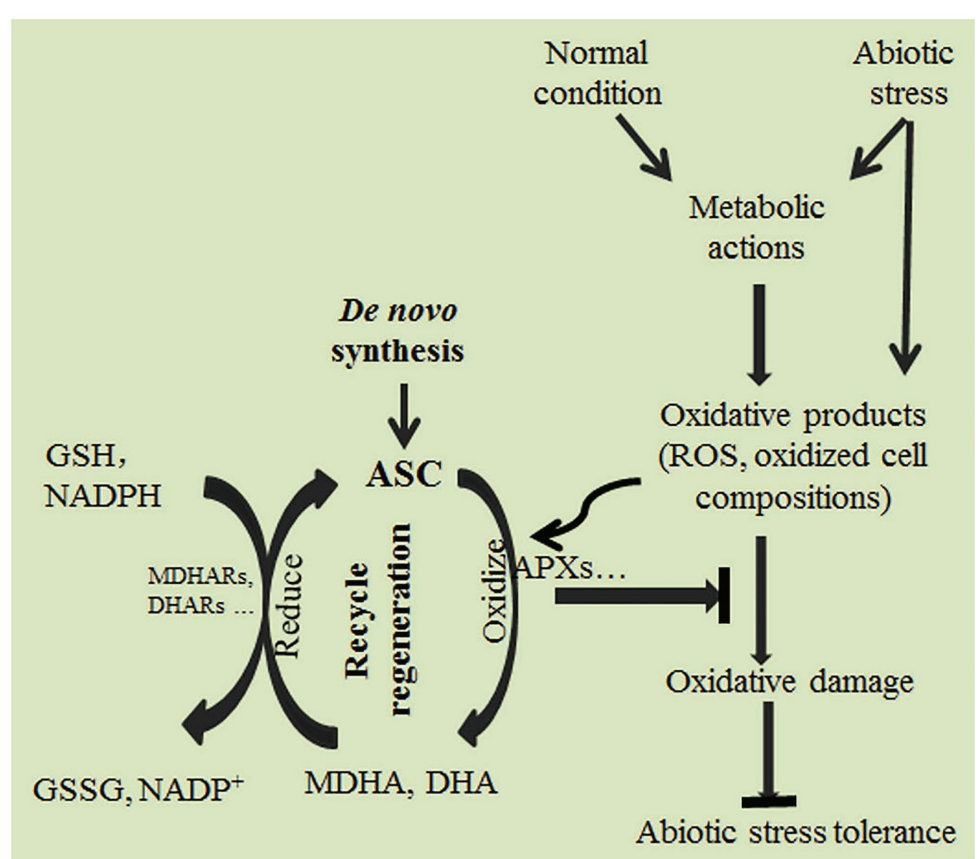

FIGURE 1 | Ascorbate (ASC) effectively scavenges reactive oxygen species (ROS), eliminates oxidative stress, and enhances abiotic stress tolerance in plants via de novo ASC synthesis and recycling.

Salinity, drought, and temperature stresses can cause ROS accumulation, resulting in severe oxidative damage (Cruz de Carvalho, 2008; Bhattacharjee, 2013; Choudhury et al., 2017). ROS scavenging is critical for plants to cope with these stresses (Sato et al., 2011; Lisko et al., 2013; Shigeoka and Maruta, 2014; Akram et al., 2017; Laxa et al., 2019; Broad et al., 2020a). Increasing ASC content by promoting ASC synthesis can enhance ROS scavenging ability and significantly improve plant stress tolerance (Hemavathi et al., 2000; Wang et al., 2011b, 2018; Zhang et al., 2012; Lisko et al., 2013; Ma et al., 2014; Ali et al., 2019; Broad et al., 2020a; Gaafar et al., 2020). In contrast, disruption of ASC de novo synthesis significantly reduces plant stress tolerance (Conklin et al., 1996; Noctor and Foyer, 1998; Huang et al., 2005; Qin et al., 2016; Wang et al., 2018).

Ascorbate regeneration via the ASC recycling pathway is also critical for plants to eliminate ROS damage and enhance abiotic stress tolerance (Sultana et al., 2012; Gallie, 2013; Caverzan et al., 2014; Sofo et al., 2015; Wang et al., 2017; Balfagón et al., 2018; Yeh et al., 2019; Broad et al., 2020b). APXs can effectively scavenge ROS with ASC, which is oxidized to monodehydroascorbate (MDHA); MDHA can then disproportionate to dehydroascorbate (DHA) and ASC (Smirnoff, 2000). ASC can be regenerated from MDHA and DHA by MDHA reductases (MDHARs) and DHA reductases (DHARs), respectively. Therefore, ASC regeneration can provide more ASC for ROS scavenging, and thus helps to maintain cell redox homeostasis and decrease oxidative damage under abiotic stress (Smirnoff, 2000; Chen et al., 2003; Li et al., 2010; Qin et al., 2011; Sultana et al., 2012; Gallie, 2013; Sofo et al., 2015; Lin et al., 2016; Broad et al., 2020b; Xiang et al., 2020). Drought can induce the expression of ASC recycling genes and thus, which enhances plant drought tolerance (Eltayeb et al., 2007; Gallie, 2013; Sofo et al., 2015; Diaz-Vivancos et al., 2016; Shan et al., 2018; Broad et al., 2020b). In tomato, the overexpression of LeMDAR improves the temperature stress tolerance of transgenic plants, whereas LeMDAR knockdown has the opposite effect (Li et al., 2010). In transgenic tobacco, the overexpression of DHAR in chloroplasts clearly enhances ROS scavenging capacity and improves plant cold tolerance (Le Martret et al., 2011). Similarly, the overexpression of DHAR enhances salt tolerance in rice, Arabidopsis, and tobacco (Kwon et al., 2003; Ushimaru et al., 2006; Le Martret et al., 2011; Sultana et al., 2012). On the contrary, deficiency of cytosolic DHAR impairs Arabidopsis abiotic stress tolerance (Yoshida et al., 2006). In summary, de novo synthesis and regeneration of ASC are both critical for plants to decrease ROS accumulation, eliminate oxidative damage, and enhance stress tolerance.

\section{AS A COFACTOR, ASC PARTICIPATES IN ABIOTIC STRESS RESPONSES BY REGULATING THE METABOLISM AND CHEMICAL MODIFICATION OF CELL COMPONENTS}

As discussed above, ASC can directly scavenge ROS as the reducible substrate of antioxidant enzymes such as APXs (Chen et al., 2014). In addition, it can act as a cofactor of violaxanthin de-epoxidase (VDE) to indirectly eliminate ROS (Mu et al., 2002; Müller-Moulé et al., 2004; Jahns et al., 2009; De Tullio, 2012; Yang et al., 2017). 
VDE uses ASC as a substrate to reduce the xanthophyll pigment violaxanthin to zeaxanthin, which is able to dissipate excess excitation energy in the photosystem II light harvesting complex and protect the photosynthesis system from photooxidative stress (Jahns et al., 2009; Saga et al., 2010; Vidal-Meireles et al., 2020). Therefore, ASC deficiency inhibits zeaxanthin accumulation, resulting in serious photooxidative damage and impairing plants' tolerance of abiotic stresses (Müller-Moulé et al., 2003, 2004; Plumb et al., 2018).

In addition to being a reducing substrate, ASC, also as a cofactor, is involved in the enzymatic reactions of several types of oxidases, such as 2-ODDs, glyceraldehyde-3-phosphate dehydrogenase, and cysteine oxidase (Jung and Wells, 1997; Shikita et al., 1999; Smirnoff, 2000; Arrigoni and De Tullio, 2002; Hedden and Thomas, 2012; Kawai et al., 2014). Among these, 2-ODDs are involved in various metabolic processes, such as protein hydroxylation and phytohormone synthesis and metabolism. These metabolic processes have important effects on plant abiotic stress responses, as well as on growth and development (Höller et al., 2015; Alegre et al., 2020; Broad et al., 2020b; Foyer et al., 2020). In humans, the role of ASC in scurvy is well understood. This disease is due to the lack of collagen, a protein critical for the structure of the extracellular matrix in humans. The collagen residues, hydroxyproline and hydroxylysine, are essential for its structural function. These residues are formed by peptidyl prolyl hydroxylases, which are 2-ODDs that need ASC as their cofactor (Myllyla et al., 1984; Myllyharju, 2003). In plants, there are several prolyl hydroxylases, such as prolyl 3-hydroxylase (P3H) and prolyl 4-hydroxylase $(\mathrm{P} 4 \mathrm{H})$, which can catalyze the hydroxyproline of polypeptides (Gorres and Raines, 2010). As in humans, plant prolyl hydroxylases also require ASC as their cofactor (Tiainen et al., 2005). Plant prolyl hydroxylases are involved in plant abiotic stress responses (Vlad et al., 2007; Asif et al., 2009; Iacopino and Licausi, 2020). They can be induced by hypoxia, and regulate the expression of hypoxia-responsive genes (Hieta and Myllyharju, 2002; Asif et al., 2009).

More importantly, several 2-ODDs, such as ACOs, NCEDs, and GA20 oxidases, are key enzymes for the synthesis of the phytohormones ethylene, ABA, and gibberellin (GA), respectively (Lange, 1994). These phytohormones are critical for plant stress responses, growth, and development (Wang et al., 2013; Colebrook et al., 2014; Sakata et al., 2014; Verma et al., 2016; Ciura and Kruk, 2018; Sahu and Kar, 2018). ASC participates in regulating plant abiotic stresses by regulating phytohormone synthesis (Sadak et al., 2013; Dinler et al., 2014; Terzi et al., 2015). For example, in wheat, ASC enhances salt tolerance by prompting the synthesis of GAs, indole acetic acid (IAA), zeatin, and brassinosteroids (BRs; Sadak et al., 2013). In tomato, higher amounts of reduced ASC contribute to induce ethylene synthesis, which further regulates fruit ripening and stress responses (Ioannidi et al., 2009). ASC can enhance maize drought tolerance by improving ABA synthesis, to decrease water loss and osmotic stress resistance (Terzi et al., 2015). Under heat stress, ASC can also enhance maize heat tolerance by decreasing ABA and IAA content, and increasing salicylic acid (SA) content (Dinler et al., 2014). Plants can coordinate the biosynthesis of different phytohormones to regulate growth and development processes, and thus adapt to internal and external conditions (Gururani et al., 2015; Verma et al., 2016; Ciura and Kruk, 2018; Sahu and Kar, 2018). GAs and ABA can be antagonistic in regulating plant growth and stress tolerance (Xu et al., 2015). ABA can suppress GA synthesis in tobacco seed embryos, thereby inhibiting germination. ASC can alter ABA and GA synthesis, thereby regulating plant growth and development processes and abiotic stress tolerance (Sadak et al., 2013; Dinler et al., 2014; Akram et al., 2017). Exogenous ASC can induce GA synthesis in tobacco seed embryos, and restore germination by counteracting the inhibitory effect of ABA on germination (Ye et al., 2012). In response to abiotic stresses, rice plants can increase $A B A$ content and suppress GA synthesis to delay germination, via ASC (Liu et al., 2010). In Arabidopsis, ASC deficiency disrupts the synthesis of several hormones, such as ABA, GA, and SA, and alters flowering time and stress tolerance (Pastori et al., 2003; Barth et al., 2004, 2006; Huang et al., 2005). The ASC deficient mutant $v t c 1$ exhibits not only decreased stress tolerance, but also accelerated flowering, due to the enhanced SA synthesis under long-day condition. In contrast, under short-day condition, $v t c 1$ exhibits delayed flowering and more rapid senescence, via the inhibition of GA synthesis and the accumulation of ABA (Pastori et al., 2003; Barth et al., 2004, 2006). These results indicate that ASC may regulate plant growth and development, enabling plants to adapt to abiotic stresses, by coordinating phytohormone synthesis (Barth et al., 2006; Xu et al., 2015).

Additionally, ASC may participate in abiotic stress responses via epigenetic pathways. For humans, Chung et al. (2010) found that ASC causes widespread DNA demethylation in embryonic stem cells. In cultured animal cells, ASC can enhance 5 -hydroxymethylcytosine $(5 \mathrm{hmC})$ generation as a cofactor for ten-eleven-translocation (TET) dioxygenase, a type of 2-ODD, which catalyzes the oxidation of 5-methylcytosine $(5 \mathrm{mC})$ into $5 \mathrm{hmC}$ (Dickson et al., 2013; Minor et al., 2013). The demethylation of genomic $5 \mathrm{mC}$ catalyzed by TET dioxygenase can lead to expression of the reprogramming gene (Young et al., 2015). Jumonji C (JMJC) histone demethylases, which are also 2-ODD enzyme, have an important role in histone demethylation. The activity of the JMJC enzymes KDM2A and KDM3A (JHMD2A) was correlated with the amount of ASC present (Tsukada et al., 2006). The histone demethylation regulated by ASC is important for regulating the chromatin state, somatic cell reprogramming, and gene expression (Wang et al., 2011a; Song et al., 2017; Zhang et al., 2019). Lu et al. (2008) showed that the function of histone demethylases, which are characterized by JMJC-type enzymes in plants, is similar to that in animals. In rice, histone demethylation has been shown to be critical for plant development and responses to abiotic stress (Chowrasia et al., 2018; Song et al., 2018). Although it has not been confirmed that TET catalyzes DNA demethylation in plants, genome-wide mapping of $5 \mathrm{hmC}$ in three rice cultivars revealed that $5 \mathrm{hmC}$ is present in significant amounts in the rice genome (Wang et al., 2015). Xue et al. (2019) showed that TET dioxygenase has an important role in the demethylation of the green alga genomic $5 \mathrm{mC}$, indicating the TET-catalyzed DNA demethylation may occur in plants. 
Further, ASC can regulate gene expression by modifying transcription factor hydroxylation. In animals, $\mathrm{P} 4 \mathrm{H}$ can catalyze the hydroxylation of the transcription factor hypoxia-inducible factor- $1 \alpha$ (HIF-1 $\alpha)$. The hydroxylation of two proline residues of HIF- $1 \alpha$ leads to its ubiquitination and degradation; in contrast, when these two proline residues are non-hydroxylated, HIF- $1 \alpha$ is transferred to the nucleus and activates the expression of downstream genes (Schofield and Ratcliffe, 2004; Frost et al., 2021). Similar to the function of $\mathrm{P} 4 \mathrm{H}$ in animals, prolyl 4-hydroxylase (AtP4H) in Arabidopsis can hydroxylate proline-rich peptides, and enhance the transcription of hypoxia-responsive marker genes under hypoxia treatment (Asif et al., 2009). In summary, as an enzyme cofactor, ASC participates in abiotic stress responses by modifying plant cell composition, coordinating phytohormone biosynthesis, and regulating gene expression via epigenetic pathways (Figure 2).

\section{AS A REGULATOR, ASC MANIPULATES STRESS SIGNAL TRANSDUCTION AND COORDINATES ABIOTIC STRESS RESPONSES}

In addition to acting as an antioxidant and cofactor, ASC also participates in plant abiotic stress responses as a regulator of plant cell signaling (De Gara et al., 2010; Choudhury et al., 2017; Waszczak et al., 2018; Bellini and De Tullio, 2019; Farooq et al., 2019; Alayafi, 2020).

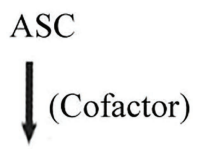

Activity of enzymes

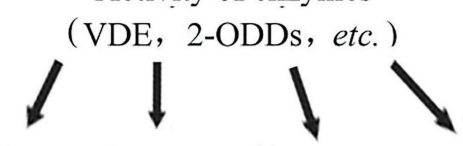

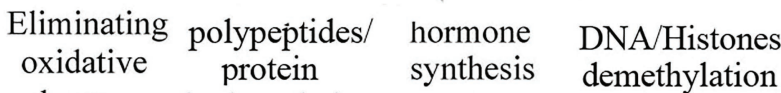
damage hydroxylation metabolism
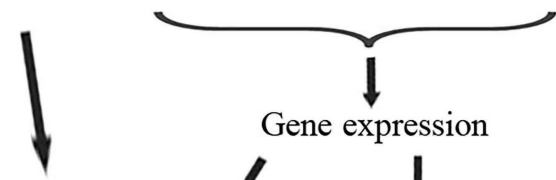

Gene expression

Stress tolerance Growth and development

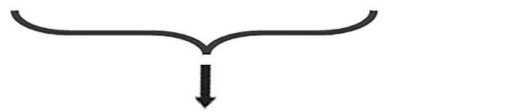

Abiotic stress tolerance

FIGURE 2 | As a cofactor of various oxidases, ASC regulates plant growth and development and abiotic stress responses, enhancing plant abiotic stress tolerance, via multiple pathways.
ASC greatly influences the actions of multiple signaling pathways, including the ROS and phytohormone signaling pathways. ASC thus integrates the actions of multiple signal pathways, and coordinates plant abiotic stress responses, by regulating the plant cell redox state (Pastori et al., 2003; Lima-Silva et al., 2012; Chen et al., 2014; Bellini and De Tullio, 2019; Bilska et al., 2019; Yu et al., 2019).

Reactive oxygen species play an important role in plant abiotic stress responses (Zhang and Guo, 2012; You and Chan, 2015; Nadarajah, 2020). In addition to causing oxidative damage, ROS can act as signaling molecules in activating the responses of plants to abiotic stresses (Foyer and Noctor, 2003; Finkel, 2011; Baxter et al., 2014; Schieber and Chandel, 2014; Choudhury et al., 2017; Hasanuzzaman et al., 2020). Therefore, the regulation of ROS homeostasis is critical for plants to adapt to abiotic stresses (Suzuki and Katano, 2018; Nadarajah, 2020). Plants can effectively manipulate cell ROS homeostasis under abiotic stress by regulating de novo ASC synthesis, or via ASC recycling regeneration (Wang et al., 2010; Gallie, 2013; Sofo et al., 2015; Noshi et al., 2017; Bilska et al., 2019; Broad et al., 2020b; Guo et al., 2020). In addition to scavenging the accumulated ROS to eliminate oxidative damage, ASC can control ROS signal transduction by regulating ROS homeostasis (Chen and Gallie, 2004; Pignocchi et al., 2006; De Tullio et al., 2013; Cobley et al., 2015; Bellini and De Tullio, 2019; Foyer et al., 2020). Unlike the enzymes involved in de novo ASC synthesis, which mainly serve to eliminate oxidative damage and maintain normal physiological and biochemical activation in plants, the enzymes that perform ASC metabolism and regeneration are also critical in regulating cell redox signals (Fotopoulos et al., 2006; Bellini and De Tullio, 2019).

ASC peroxidases, which are critical enzymes in ASC metabolism, play an important role in both ROS scavenging and manipulating the activity of various cell signaling pathways. APXs are distributed in various organs and are involved in sustaining cellular redox homeostasis (Bonifacio et al., 2011; Chen et al., 2014; Maruta et al., 2016; Yu et al., 2019). In Arabidopsis, the deficiency of APX6 activity decreases the content of reduced ASC in the seed, and promotes DHA accumulation, which disrupts cell redox homeostasis and further affects the action of ROS, ABA, and auxin signaling pathways (Chen et al., 2014). Similarly, silencing of Arabidopsis thylakoid membrane-bound APX disturbs the expression of downstream genes in the $\mathrm{H}_{2} \mathrm{O}_{2}$ signaling pathway of chloroplasts (Maruta et al., 2012, 2016).

Ascorbate oxidases (AOs), which also oxidize ASC to MDHA, are involved in cell signal transduction (Szarka et al., 2004; Pignocchi et al., 2006; Li et al., 2007, 2017; De Tullio et al., 2013; Bellini and De Tullio, 2019; Pan et al., 2019). Unlike APXs, which are located in various parts of plant cells, AOs are mostly located in the cell wall, and oxidize apoplastic ASC (Pignocchi et al., 2006; De Tullio et al., 2013). In the apoplast, MDHA arising from ASC oxidation by AOs can be converted to DHA and rapidly transported into the cytoplasm, where it can then be recycled into ASC by DHARs. In contrast, the reduced ASC in the cytoplasm can be transferred to the apoplast, resulting in ASC exchange between the apoplast and cytoplasm. This DHA-ASC exchange is critical for 
maintaining redox homeostasis in both the apoplast and cytoplasm (Sanmartin et al., 2003; Fotopoulos et al., 2006; De Tullio et al., 2013; Gallie, 2013; Pan et al., 2019; Foyer et al., 2020). Under abiotic stress, the DHA flux from apoplastic oxidization of ASC increases rapidly and disrupts the balance of the redox state in the apoplast and cytoplasm; this acts as a signal to initiate a response to adverse environmental conditions (Horemans et al., 2000; Sanmartin et al., 2007). The expression of AOs can be induced by abiotic stresses, and their expression level has an important effect on plant abiotic stress tolerance (Esaka et al., 1992; Li et al., 2017; Pan et al., 2019). Another difference between APXs and AOs is that APXs oxidize ASC by using $\mathrm{H}_{2} \mathrm{O}_{2}$, whereas AOs consume ASC by using $\mathrm{O}_{2}$. The oxidized ASC (DHA) can further produce various metabolites by AOs under plant apoplastic conditions. Among these products, some may delay APXs action and inhibit ROS scavenging. Moreover, some products, such as 2,3-diketogulonate, produce $\mathrm{H}_{2} \mathrm{O}_{2}$ by AOs or non-enzymatical pathway (Parsons and Fry, 2012; Kärkönen et al., 2017; Dewhirst and Fry, 2018; Smirnoff, 2018; Dewhirst et al., 2020). Therefore, unlike APXs, which use ASC to scavenge ROS and eliminate oxidative damage, AOs consume ASC to accelerate the accumulation of ROS in apoplast. Thus, the overexpression of AOs decreases abiotic stress tolerance, due to the enhanced activities of AOs both disrupting the normal stress signal flux from the apoplast to the cytoplasm and increasing the oxidative damage from the accumulated ROS (Fotopoulos et al., 2006; Garchery et al., 2013). The role of AOs in regulating the activity of cell signaling pathways has been demonstrated by the discovery of close links between AOs and ROS signaling in the stress response, growth, and development of cotton (Li et al., 2007, 2017; Pan et al., 2019; $\mathrm{Yu}$ et al., 2019). The expression of the cotton AO genes GhAO1 and GhAO1A can modulate apoplastic ROS homeostasis and hormone signaling, which affects not only plant stress tolerance, but also cell elongation and leaf senescence, respectively ( $\mathrm{Li}$ et al., 2007, 2017; Pan et al., 2019).

Ascorbate regeneration is also involved in regulating plant signaling. DHARs are responsible for the regeneration of ASC from DHA, which plays an important role in transmitting abiotic stress signals (Chen and Gallie, 2004; Rahantaniaina et al., 2017). For example, DHAR-overexpression in the stoma of tobacco promotes the production of reduced ASC and decreases plant drought tolerance; because it blocks guard cells from responding to $\mathrm{ABA}$ and $\mathrm{H}_{2} \mathrm{O}_{2}$ signaling, and keeps stomatal opening and increases water loss (Chen and Gallie, 2004). In contrast, suppressing DHAR expression in stoma promotes $\mathrm{H}_{2} \mathrm{O}_{2}$ accumulation, which triggers $\mathrm{ABA}$ and $\mathrm{H}_{2} \mathrm{O}_{2}$ signaling, promoting stomatal closure and decreasing water loss; suppressing DHAR activity in the stoma can therefore enhance drought tolerance (Chen and Gallie, 2004; Gallie, 2013).

The ratio of ASC to DHA (ASC/DHA ratio) plays an important role in transmitting plant cellular redox signal (Pignocchi and Foyer, 2003; Chen and Gallie, 2004; De Tullio et al., 2013; Sierla et al., 2013; Cobley et al., 2015). ROS functions are closely related to their concentrations. At low concentrations, they act as signaling molecules to activate the plant stress response system to cope with adverse condition, whereas at high concentrations, they cause oxidative damage to plants (Schieber and Chandel, 2014; Choudhury et al., 2017). According to the ROS content, plants take different measures to deal with ROS (Figure 3). When ROS are present at low levels, and act as signaling molecules, plants can utilize ROS to transmit the cellular redox state signal, by using ASC to negatively regulate the ROS signaling. In contrast, when ROS are present at high levels, plants use ASC to scavenge ROS, to avoid the oxidative damage caused by ROS, and use the ASC-DHA redox couple to transmit the cellular redox state signal (Noctor and Foyer, 1998; Smirnoff and Wheeler, 2000; Potters et al., 2010; Schieber and Chandel, 2014; Choudhury et al., 2017). The ASC/DHA ratio is therefore central for plants to transfer abiotic stress signals caused by adverse environmental conditions (de Pinto et al., 1999; Foyer and Noctor, 2003; Eastmond, 2007; Anjum et al., 2014; Foyer et al., 2020). The ASC/DHA ratio can affect the action of auxin- and calcium-ion signaling, and further affect the abiotic stress response (Pignocchi and Foyer, 2003; Yamamoto et al., 2005; Fotopoulos et al., 2006; Pignocchi et al., 2006; Sanmartin et al., 2007). The low ASC/DHA ratio in the apoplast inhibits the response of plants to auxin, which is due to the inhibition of auxin signal transduction across the plasma membrane (Barbier-Brygoo et al., 1989; Pignocchi and Foyer, 2003; Pignocchi et al., 2006). DHAR deficiency decreases the ASC/ DHA ratio and impairs SA signaling in Arabidopsis (Rahantaniaina et al., 2017). Under copper stress, impaired DHAR expression substantially decreases the ASC/DHA ratio and blocks the MAPK signaling pathway, in order to cope with copper stress (Rodríguez-Rojas et al., 2019). Therefore, a high ASC/DHA ratio can represent a strong ability to cope with abiotic stress. For instance, in Arabidopsis, impaired MDAR4 function decreased the AsA/DHA ratio without affecting the ASC content, but substantially impaired plant oxidative stress tolerance (Eastmond, 2007). In tobacco, SA can elevate DHAR activity and increase the ASC/DHA ratio, which can prompt the scavenging of ROS accumulated by abiotic stress, and thus enhance plant salt tolerance (Yan et al., 2018).

The question arises of how the roles of ASC in scavenging ROS and regulating ROS signal under abiotic stresses can be distinguished. Before answering this question, it is necessary to analyze the role of ASC in plant abiotic stress responses. Studies have shown that ACS plays a double role in the response to abiotic stress, and in growth and development (De Tullio, 2012). As Bellini and De Tullio (2019) discussed for the role of ASC under ozone treatment, there is no evidence that ASC content or the activity of ASC regeneration enzymes is related to the antioxidant capacity of plants. Although high ASC content or strong ASC regeneration capacity is considered to improve plant abiotic stress tolerance, there are many cases in which enhancing ASC content or regenerating enzyme activity decreases plants abiotic stress tolerance. The importance of ASC in transmitting abiotic stress-related signals may well explain why ASC enhances ROS scavenging ability, but results in decreased plant abiotic stress tolerance (De Tullio et al., 2013). ROS cause oxidative damage, but also play an important role in activating 


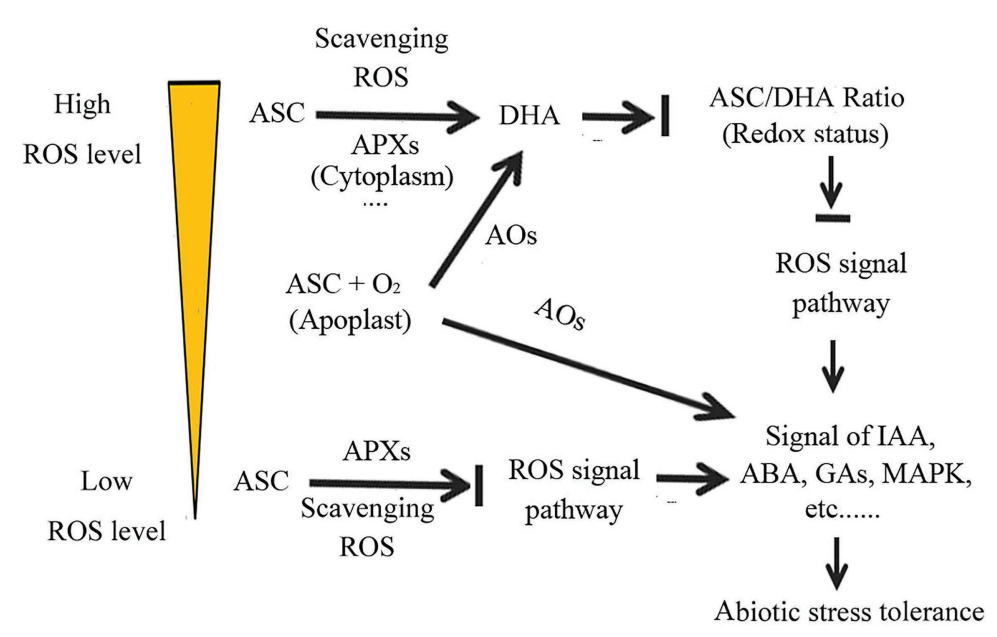

FIGURE 3 | Ascorbate regulates the cellular redox state, thereby coordinating various signaling pathways, to enhance plant adaptability to abiotic stress.

the responses of plants to stresses (Foyer and Noctor, 2003; Finkel, 2011; Baxter et al., 2014). "Hormesis" refers to a phenomenon in which low levels of the stressor induce optimal plant growth, whereas higher levels of the same stressor damage plants (Oliveira et al., 2018). Enhanced ROS scavenging ability disrupts the generation of ROS signals, which are responsible for the transmission of abiotic stress signals under low ROS levels. Inhibition of the ROS signaling pathway severely delays or impairs plant "hormesis" effect, and decreases plants abiotic stress tolerane (Calabrese and Mattson, 2017; Agathokleous et al., 2019).

Ascorbate may induce a biphasic response in plants under abiotic stresses. In ABA- and ROS-mediated stress responses, ASC exhibits this biphasic response to environmental stress (De Tullio, 2012). ABA may play a dual role in regulating plant ROS levels under abiotic stress. In the early stage of stress response, ABA promotes ROS production and activates ROS signaling, thereby helping plants to respond rapidly to adverse environmental conditions (Kwak et al., 2003; Liu et al., 2010; Sahu and Kar, 2018). In contrast, during the late stage of stress adaptation, ABA activates the de novo synthesis and regeneration of ASC to scavenge the accumulated ROS and thus eliminate oxidative damage, to enhance plant abiotic stress tolerance (Zhang et al., 2020). This may explain why ABA inhibits ASC synthesis and accelerates ROS accumulation in some circumstances (Jiang and Zhang, 2002; Kwak et al., 2003; Yu et al., 2019), but induces ASC synthesis and ROS scavenging in others (Jiang and Zhang, 2002; Zhang et al., 2020). Therefore, we hypothesize that ASC plays a more important role in regulating plant stress signal transduction at low cellular oxidation levels, and a more critical role in scavenging ROS at high cellular oxidation levels (Figure 3). In fact, in some cases, ASC may play different roles at the same time. In the apoplast, ASC does not protect cell wall components from oxidative damage, instead being involved in external signal transduction. ASC can act as a cofactor to keep iron $(\mathrm{Fe})$ in the $\mathrm{Fe}^{2+}$ state and protect 2-ODDs from oxidative damage (Myllyla et al., 1984;
Kivirikko and Pihlajaniemi, 1998; Wu et al., 2000; Hoffart et al., 2006). In summary, ASC can integrate the actions of multiple signaling pathways by modulating the cell redox state; this integration is critical in abiotic stress responses. The role of ASC in cell signal transduction is related to its cellular location, the ROS concentration, and the stage of the plant stress response (Figure 3 ).

\section{DISCUSSION AND CONCLUSION}

Antioxidation is traditionally considered as the primary role of ASC in plant responses to abiotic stresses (Noctor and Foyer, 1998). However, ASC has been shown to act as an enzyme cofactor or regulator of cell signaling, coordinating phytohormone synthesis, and the actions of various signaling pathways, thereby adjusting plant growth and development processes and stress responses in adaptation to ever-changing internal and external conditions (Arrigoni and De Tullio, 2002; De Tullio, 2012; Bellini and De Tullio, 2019; Foyer et al., 2020).

Ascorbate plays multiple roles in abiotic stress responses. First, as an antioxidant, ASC directly or indirectly scavenges the ROS produced by abiotic stress, to eliminate oxidative damage and enhance plant abiotic stress tolerance (Figure 1). Second, as a cofactor, it regulates the synthesis and metabolism of various cell components, including phytohormones, thereby profoundly influencing the integration of plant stress responses and growth and development processes (Figure 2). Third, it can regulate the activities of various signaling pathways (Figure 3). In responding to abiotic stress, plants effectively coordinate the actions of various signaling pathways, such as hormone, ROS, and MAPK signaling pathways, by quickly regulating cellular redox signaling via ASC (by altering the ASC/DHA ratio), thereby rapidly responding and adapting to abiotic stresses (Pastori et al., 2003; Ye et al., 2012; Smirnoff, 2018). Notably, the roles of ASC in plant responses to abiotic stress should be analyzed according to its specific cellular 
location, the cellular ROS content, and the stage of the stress response (Zechmann, 2018).

Ascorbate is a complex and multifaceted cellular compound, with many functions that remain to be elucidated in plants. Although its central role in regulating plant redox signals has been well described, the mechanisms by which it regulates the cell redox status to coordinate the balance between cell redox signaling and ROS scavenging remain unknown. The fluctuation of the ASC/DHA ratio has important effects on growth and development processes and plant adaptation to abiotic stresses; nonetheless, it remains unclear what regulatory mechanisms and pathways are involved in maintaining the dynamic balance of ASC/DHA ratio (Yamamoto et al., 2005; Tripathi et al., 2012; Foyer et al., 2020). In addition, in animals, ASC participates in regulating gene expression, is involved in DNA and histone demethylation, and alters the cell cycle via epigenetic pathways (Blaschke et al., 2013; Xue et al., 2019). However, its role in DNA demethylation in plants remains unclear. Further studies on the effects and roles of ASC in the plant epigenome will expand the understanding of this important micronutrient.

\section{REFERENCES}

Agathokleous, E., Kitao, M., and Calabrese, E. J. (2019). Hormesis: a compelling platform for sophisticated plant science. Trends Plant Sci. 24, 318-327. doi: 10.1016/j.tplants.2019.01.004

Akram, N. A., Shafiq, F., and Ashraf, M. (2017). Ascorbic acid-a potential oxidant scavenger and its role in plant development and abiotic stress tolerance. Front. Plant Sci. 8:613. doi: 10.3389/fpls.2017.00613

Alayafi, A. A. M. (2020). Exogenous ascorbic acid induces systemic heat stress tolerance in tomato seedlings: transcriptional regulation mechanism. Environ. Sci. Pollut. Res. Int. 27, 19186-19199. doi: 10.1007/s11356019-06195-7

Alegre, M. L., Steelheart, C., Baldet, P., Rothan, C., Just, D., Okabe, Y., et al. (2020). Deficiency of GDP-L-galactose phosphorylase, an enzyme required for ascorbic acid synthesis, reduces tomato fruit yield. Planta 251:54. doi: 10.1007/s00425-020-03345-X

Ali, B., Pantha, S., Acharya, R., Ueda, Y., Wu, L. B., Ashrafuzzaman, M., et al. (2019). Enhanced ascorbate level improves multi-stress tolerance in a widely grown indica rice variety without compromising its agronomic characteristics. J. Plant Physiol. 240:152998. doi: 10.1016/j.jplph.2019.152998

Anjum, N. A., Gill, S. S., Gill, R., Hasanuzzaman, M., Duarte, A. C., Pereira, E., et al. (2014). Metal/metalloid stress tolerance in plants: role of ascorbate, its redox couple, and associated enzymes. Protoplasma 251, 1265-1283. doi: 10.1007/s00709-014-0636-x

Arrigoni, O., and De Tullio, M. C. (2002). Ascorbic acid: much more than just an antioxidant. Biochim. Biophys. Acta 1569, 1-9. doi: 10.1016/ s0304-4165(01)00235-5

Asif, M. H., Trivedi, P. K., Misra, P., and Nath, P. (2009). Prolyl-4-hydroxylase (AtP4H1) mediates and mimics low oxygen response in Arabidopsis thaliana. Funct. Integr. Genomics 9, 525-535. doi: 10.1007/s10142-009-0118-y

Balfagón, D., Zandalinas, S. I., Baliño, P., Muriach, M., and Gómez-Cadenas, A. (2018). Involvement of ascorbate peroxidase and heat shock proteins on citrus tolerance to combined conditions of drought and high temperatures. Plant Physiol. Biochem. 127, 194-199. doi: 10.1016/j.plaphy.2018.03.029

Barbier-Brygoo, H., Ephritikhine, G., Klämbt, D., Ghislain, M., and Guern, J. (1989). Functional evidence for an auxin receptor at the plasmalemma of tobacco mesophyll protoplasts. Proc. Natl. Acad. Sci. U. S. A. 86, 891-895. doi: 10.1073 /pnas.86.3.891

Baron, J. H. (2009). Sailors' scurvy before and after James Lind-a reassessment. Nutr. Rev. 67, 315-332. doi: 10.1111/j.1753-4887.2009.00205.x

\section{AUTHOR CONTRIBUTIONS}

MX, BpZ, FZ, HZ, and YW: wrote introduction, discussion, and ASC as a cofactor. ZL and JW: wrote ascorbate as an antioxidant. LZ, MX, and FZ: wrote ASC as a regulator. ZL, YW, BoZ, FZ, and LZ: original draft preparation. MX, ZL, LZ, JW, and ZZ: writing review and editing. ZZ: supervision and funding acquisition. All authors contributed to the article and approved the submitted version.

\section{FUNDING}

This work was financially supported through grants from the National Basic Research Program of China (grant no: 31971838 and grant no: 31670304 ) and National Transgenic Major Program (grant no: 2018ZX08001-002), Fundamental Research Funds for Central Non-profit Scientific Institution (Y2017PT25) and the National Key Research and Development Program of China (2018YFD1000702), and The Agricultural Science and Technology Innovation Program (ASTIP).

Barth, C., De Tullio, M., and Conklin, P. L. (2006). The role of ascorbic acid in the control of flowering time and the onset of senescence. J. Exp. Bot. 57, 1657-1665. doi: 10.1093/jxb/erj198

Barth, C., Moeder, W., Klessig, D. F., and Conklin, P. L. (2004). The timing of senescence and response to pathogens is altered in the ascorbate-deficient Arabidopsis mutant vitamin c-1. Plant Physiol. 134, 1784-1792. doi: 10.1104/ pp.103.032185

Baxter, A., Mittler, R., and Suzuki, N. (2014). ROS as key players in plant stress signalling. J. Exp. Bot. 65, 1229-1240. doi: 10.1093/jxb/ert375

Bellini, E., and De Tullio, M. C. (2019). Ascorbic acid and ozone: novel perspectives to explain an elusive relationship. Plan. Theory 8:122. doi: $10.3390 /$ plants 8050122

Bhattacharjee, S. (2013). Heat and chilling induced disruption of redox homeostasis and its regulation by hydrogen peroxide in germinating rice seeds (Oryza sativa L., cultivar Ratna). Physiol. Mol. Biol. Plants 19, 199-207. doi: 10.1007/ s12298-012-0159-x

Bilska, K., Wojciechowska, N., Alipour, S., and Kalemba, E. M. (2019). Ascorbic acid-the little-known antioxidant in woody plants. Antioxidants 8:645. doi: 10.3390/antiox8120645

Blaschke, K., Ebata, K. T., Karimi, M. M., Zepeda-Martínez, J. A., Goyal, P., Mahapatra, S., et al. (2013). Vitamin C induces Tet-dependent DNA demethylation and a blastocyst-like state in ES cells. Nature 500, 222-226. doi: $10.1038 /$ nature 12362

Bonifacio, A., Martins, M. O., Ribeiro, C. W., Fontenele, A. V., Carvalho, F. E., Margis-Pinheiro, M., et al. (2011). Role of peroxidases in the compensation of cytosolic ascorbate peroxidase knockdown in rice plants under abiotic stress. Plant Cell Environ. 34, 1705-1722. doi: 10.1111/j.1365-3040.2011.02366.x

Brisson, L., El Bakkali-Taheri, N., Giorgi, M., Fadel, A., Kaizer, J., Réglier, M., et al. (2012). 1-Aminocyclopropane-1-carboxylic acid oxidase: insight into cofactor binding from experimental and theoretical studies. J. Biol. Inorg. Chem. 17, 939-949. doi: 10.1007/s00775-012-0910-3

Broad, R. C., Bonneau, J. P., Beasley, J. T., Roden, S., Sadowski, P., Jewell, N., et al. (2020a). Effect of rice GDP-L-galactose phosphorylase constitutive overexpression on ascorbate concentration, stress tolerance, and iron bioavailability in rice. Front. Plant Sci. 11:595439. doi: 10.3389/fpls.2020. 595439

Broad, R. C., Bonneau, J. P., Hellens, R. P., and Johnson, A. A. T. (2020b). Manipulation of ascorbate biosynthetic, recycling, and regulatory pathways for improved abiotic stress tolerance in plants. Int. J. Mol. Sci. 21:1790. doi: $10.3390 /$ ijms 21051790 
Calabrese, E. J., and Mattson, M. P. (2017). How does hormesis impact biology, toxicology, and medicine? NPJ Aging Mech. Dis. 3:13. doi: 10.1038/s41514017-0013-z

Carpenter, K. J. (2012). The discovery of vitamin C. Ann. Nutr. Metab. 61, 259-264. doi: 10.1159/000343121

Caverzan, A., Bonifacio, A., Carvalho, F. E., Andrade, C. M., Passaia, G., Schünemann, M., et al. (2014). The knockdown of chloroplastic ascorbate peroxidases reveals its regulatory role in the photosynthesis and protection under photo-oxidative stress in rice. Plant Sci. 214, 74-87. doi: 10.1016/j. plantsci.2013.10.001

Chen, Z., and Gallie, D. R. (2004). The ascorbic acid redox state controls guard cell signaling and stomatal movement. Plant Cell 16, 1143-1162. doi: $10.1105 /$ tpc. 021584

Chen, C., Letnik, I., Hacham, Y., Dobrev, P., Ben-Daniel, B. H., Vanková, R., et al. (2014). Ascorbate peroxidase 6 protects Arabidopsis desiccating and germinating seeds from stress and mediates cross talk between reactive oxygen species, abscisic acid, and auxin. Plant Physiol. 166, 370-383. doi: 10.1104/pp.114.245324

Chen, Z., Young, T. E., Ling, J., Chang, S. C., and Gallie, D. R. (2003). Increasing vitamin $\mathrm{C}$ content of plants through enhanced ascorbate recycling. Proc. Natl. Acad. Sci. U. S. A. 100, 3525-3530. doi: 10.1073/pnas.0635176100

Choudhury, F. K., Rivero, R. M., Blumwald, E., and Mittler, R. (2017). Reactive oxygen species, abiotic stress and stress combination. Plant J. 90, 856-867. doi: $10.1111 /$ tpj.13299

Chowrasia, S., Panda, A. K., Rawal, H. C., Kaur, H., and Mondal, T. K. (2018). Identification of JumonjiC domain containing gene family among the Oryza species and their expression analysis in FL478, a salt tolerant rice genotype. Plant Physiol. Biochem. 130, 43-53. doi: 10.1016/j.plaphy.2018.06.031

Chung, T. L., Brena, R. M., Kolle, G., Grimmond, S. M., Berman, B. P., Laird, P. W., et al. (2010). Vitamin C promotes widespread yet specific DNA demethylation of the epigenome in human embryonic stem cells. Stem Cells 28, 1848-1855. doi: 10.1002/stem.493

Ciura, J., and Kruk, J. (2018). Phytohormones as targets for improving plant productivity and stress tolerance. J. Plant Physiol. 229, 32-40. doi: 10.1016/j. jplph.2018.06.013

Cobley, J. N., McHardy, H., Morton, J. P., Nikolaidis, M. G., and Close, G. L. (2015). Influence of vitamin $C$ and vitamin $\mathrm{E}$ on redox signaling: implications for exercise adaptations. Free Radic. Biol. Med. 84, 65-76. doi: 10.1016/j. freeradbiomed.2015.03.018

Colebrook, E. H., Thomas, S. G., Phillips, A. L., and Hedden, P. (2014). The role of gibberellin signaling in plant responses to abiotic stress. J. Exp. Biol. 217, 67-75. doi: 10.1242/jeb.089938

Conklin, P. L., Williams, E. H., and Last, R. L. (1996). Environmental stress sensitivity of an ascorbic acid-deficient Arabidopsis mutant. Proc. Natl. Acad. Sci. U. S. A. 93, 9970-9974. doi: 10.1073/pnas.93.18.9970

Cruz de Carvalho, M. H. (2008). Drought stress and reactive oxygen species: production, scavenging and signaling. Plant Signal. Behav. 3, 156-165. doi: $10.4161 /$ psb.3.3.5536

De Gara, L., Locato, V., Dipierro, S., and de Pinto, M. C. (2010). Redox homeostasis in plants. The challenge of living with endogenous oxygen production. Respir. Physiol. Neurobiol. 173, S13-S19. doi: 10.1016/j.resp.2010.02.007

de Pinto, M. C., and De Gara, L. (2004). Changes in the ascorbate metabolism of apoplastic and symplastic spaces are associated with cell differentiation. J. Exp. Bot. 55, 2559-2569. doi: 10.1093/jxb/erh253

de Pinto, M. C., Francis, D., and De Gara, L. (1999). The redox state of the ascorbate-dehydroascorbate pair as a specific sensor of cell division in tobacco BY-2 cells. Protoplasma 209, 90-97. doi: 10.1007/BF01415704

De Tullio, M. C. (2012). Beyond the antioxidant: the double life of vitamin C. Subcell. Biochem. 56, 49-65. doi: 10.1007/978-94-007-2199-9_4

De Tullio, M. C., Guether, M., and Balestrini, R. (2013). Ascorbate oxidase is the potential conductor of a symphony of signaling pathways. Plant Signal. Behav. 8:e23213. doi: 10.4161/psb.23213

Dewhirst, R. A., and Fry, S. C. (2018). The oxidation of dehydroascorbic acid and 2,3-diketogulonate by distinct reactive oxygen species. Biochem. J. 475, 3451-3470. doi: 10.1042/BCJ20180688

Dewhirst, R. A., Murray, L., Mackay, C. L., Sadler, I. H., and Fry, S. C. (2020). Characterisation of the non-oxidative degradation pathway of dehydroascorbic acid in slightly acidic aqueous solution. Arch. Biochem. Biophys. 681:108240. doi: $10.1016 /$ j.abb.2019.108240
Diaz-Vivancos, P., Faize, L., Nicolás, E., Clemente-Moreno, M. J., Bru-Martinez, R., Burgos, L., et al. (2016). Transformation of plum plants with a cytosolic ascorbate peroxidase transgene leads to enhanced water stress tolerance. Ann. Bot. 117, 1121-1131. doi: 10.1093/aob/mcw045

Dickson, K. M., Gustafson, C. B., Young, J. I., Züchner, S., and Wang, G. (2013). Ascorbate-induced generation of 5-hydroxymethylcytosine is unaffected by varying levels of iron and 2-oxoglutarate. Biochem. Biophys. Res. Commun. 439, 522-527. doi: 10.1016/j.bbrc.2013.09.010

Ding, H., Wang, B., Han, Y., and Li, S. (2020). The pivotal function of dehydroascorbate reductase in glutathione homeostasis in plants. J. Exp. Bot. 71, 3405-3416. doi: 10.1093/jxb/eraa107

Dinler, B. S., Demir, E., and Kompe, Y. O. (2014). Regulation of auxin, abscisic acid and salicylic acid levels by ascorbate application under heat stress in sensitive and tolerant maize leaves. Acta Biol. Hung. 65, 469-480. doi: 10.1556/ ABiol.65.2014.4.10

Dumanović, J., Nepovimova, E., Natić, M., Kuča, K., and Jaćević, V. (2020). The significance of reactive oxygen species and antioxidant defense system in plants: a concise overview. Front. Plant Sci. 11:552969. doi: 10.3389/ fpls.2020.552969

Dumont, S., and Rivoal, J. (2019). Consequences of oxidative stress on plant glycolytic and respiratory metabolism. Front. Plant Sci. 10:166. doi: 10.3389/ fpls.2019.00166

Eastmond, P. J. (2007). MONODEHYROASCORBATE REDUCTASE4 is required for seed storage oil hydrolysis and postgerminative growth in Arabidopsis. Plant Cell 19, 1376-1387. doi: 10.1105/tpc.106.043992

Elkelish, A., Qari, S. H., Mazrou, Y. S. A., Abdelaal, K. A. A., Hafez, Y. M., Abu-Elsaoud, A. M., et al. (2020). Exogenous ascorbic acid induced chilling tolerance in tomato plants through modulating metabolism, osmolytes, antioxidants, and transcriptional regulation of catalase and heat shock proteins. Plan. Theory 9:431. doi: 10.3390/plants9040431

Eltayeb, A. E., Kawano, N., Badawi, G. H., Kaminaka, H., Sanekata, T., Shibahara, T., et al. (2007). Overexpression of monodehydroascorbate reductase in transgenic tobacco confers enhanced tolerance to ozone, salt and polyethylene glycol stresses. Planta 225, 1255-1264. doi: 10.1007/s00425-006-0417-7

Esaka, M., Fujisawa, K., Goto, M., and Kisu, Y. (1992). Regulation of ascorbate oxidase expression in pumpkin by auxin and copper. Plant Physiol. 100, 231-237. doi: 10.1104/pp.100.1.231

Farooq, M. A., Niazi, A. K., Akhtar, J., Saifullah, , Farooq, M., Souri, Z., et al. (2019). Acquiring control: the evolution of ROS-induced oxidative stress and redox signaling pathways in plant stress responses. Plant Physiol. Biochem. 141, 353-369. doi: 10.1016/j.plaphy.2019.04.039

Finkel, T. (2011). Signal transduction by reactive oxygen species. J. Cell Biol. 194, 7-15. doi: 10.1083/jcb.201102095

Fotopoulos, V., Sanmartin, M., and Kanellis, A. K. (2006). Effect of ascorbate oxidase over-expression on ascorbate recycling gene expression in response to agents imposing oxidative stress. J. Exp. Bot. 57, 3933-3943. doi: 10.1093/ jxb/erl147

Foyer, C. H. (2018). Reactive oxygen species, oxidative signaling and the regulation of photosynthesis. Environ. Exp. Bot. 154, 134-142. doi: 10.1016/j. envexpbot.2018.05.003

Foyer, C. H., Kyndt, T., and Hancock, R. D. (2020). Vitamin C in plants: novel concepts, new perspectives, and outstanding issues. Antioxid. Redox Signal. 32, 463-485. doi: 10.1089/ars.2019.7819

Foyer, C. H., and Noctor, G. (2003). Redox sensing and signalling associated with reactive oxygen in chloroplasts, peroxisomes and mitochondria. Physiol. Plant. 119, 355-364. doi: 10.1034/j.1399-3054.2003.00223.x

Frost, J., Frost, M., Batie, M., Jiang, H., and Rocha, S. (2021). Roles of HIF and 2-oxoglutarate-dependent dioxygenases in controlling gene expression in hypoxia. Cancer 13:350. doi: 10.3390/cancers 13020350

Gaafar, A. A., Ali, S. I., El-Shawadfy, M. A., Salama, Z. A., Sekara, A., Ulrichs, C., et al. (2020). Ascorbic acid induces the increase of secondary metabolites, antioxidant activity, growth, and productivity of the common bean under water stress conditions. Plan. Theory 9:627. doi: 10.3390/ plants 9050627

Gallie, D. R. (2013). The role of L-ascorbic acid recycling in responding to environmental stress and in promoting plant growth. J. Exp. Bot. 64, 433-444. doi: 10.1093/jxb/ers330

Garchery, C., Gest, N., Do, P. T., Alhagdow, M., Baldet, P., Menard, G., et al. (2013). Diminution in ascorbate oxidase activity affects carbon allocation 
and improves yield in tomato under water deficit. Plant Cell Environ. 36, 159-175. doi: 10.1111/j.1365-3040.2012.02564.x

Gill, S. S., and Tuteja, N. (2010). Reactive oxygen species and antioxidant machinery in abiotic stress tolerance in crop plants. Plant Physiol. Biochem. 48, 909-930. doi: 10.1016/j.plaphy.2010.08.016

Gorres, K. L., and Raines, R. T. (2010). Prolyl 4-hydroxylase. Crit. Rev. Biochem. Mol. Biol. 45, 106-124. doi: 10.3109/10409231003627991

Guo, K., Li, Z., Tian, H., Du, X., Liu, Z., Huang, H., et al. (2020). Cytosolic ascorbate peroxidases plays a critical role in photosynthesis by modulating reactive oxygen species level in stomatal guard cell. Front. Plant Sci. 11:446. doi: $10.3389 /$ fpls.2020.00446

Gururani, M. A., Mohanta, T. K., and Bae, H. (2015). Current understanding of the interplay between phytohormones and photosynthesis under environmental stress. Int. J. Mol. Sci. 16, 19055-19085. doi: 10.3390/ijms160819055

Hasanuzzaman, M., Bhuyan, M. H. M. B., Anee, T. I., Parvin, K., Nahar, K., Mahmud, J. A., et al. (2019). Regulation of ascorbate-glutathione pathway in mitigating oxidative damage in plants under abiotic stress. Antioxidants 8:384. doi: 10.3390/antiox8090384

Hedden, P., and Thomas, S. G. (2012). Gibberellin biosynthesis and its regulation. Biochem. J. 444, 11-25. doi: 10.1042/BJ20120245

Hemavathi, , Upadhyaya, C. P., Akula, N., Young, K. E., Chun, S. C., Kim, D. H., et al. (2000). Enhanced ascorbic acid accumulation in transgenic potato confers tolerance to various abiotic stresses. Biotechnol. Lett. 32, 321-330. doi: 10.1007/s10529-009-0140-0

Hieta, R., and Myllyharju, J. (2002). Cloning and characterization of a low molecular weight prolyl 4-hydroxylase from Arabidopsis thaliana. Effective hydroxylation of proline-rich, collagen-like, and hypoxia-inducible transcription factor alpha-like peptides. J. Biol. Chem. 277, 23965-23971. doi: 10.1074/ jbc.M201865200

Hoffart, L. M., Barr, E. W., Guyer, R. B., Bollinger, J. M. Jr., and Krebs, C. (2006). Direct spectroscopic detection of a C-H-cleaving high-spin Fe(IV) complex in a prolyl-4-hydroxylase. Proc. Natl. Acad. Sci. U. S. A. 103, 14738-14743. doi: 10.1073/pnas.0604005103

Höller, S., Ueda, Y., Wu, L., Wang, Y., Hajirezaei, M. R., Ghaffari, M. R., et al. (2015). Ascorbate biosynthesis and its involvement in stress tolerance and plant development in rice (Oryza sativa L.). Plant Mol. Biol. 88, 545-560. doi: 10.1007/s11103-015-0341-y

Horemans, N., Foyer, C. H., and Asard, H. (2000). Transport and action of ascorbate at the plant plasma membrane. Trends Plant Sci. 5, 263-267. doi: 10.1016/S1360-1385(00)01649-6

Houben, M., and Van de Poel, B. (2019). 1-Aminocyclopropane-1-carboxylic acid oxidase (ACO): the enzyme that makes the plant hormone ethylene. Front. Plant Sci. 10:695. doi: 10.3389/fpls.2019.00695

Huang, C., He, W., Guo, J., Chang, X., Su, P., and Zhang, L. (2005). Increased sensitivity to salt stress in an ascorbate-deficient Arabidopsis mutant. J. Exp. Bot. 422, 3041-3049. doi: 10.1093/jxb/eri301

Iacopino, S., and Licausi, F. (2020). The contribution of plant dioxygenases to hypoxia signaling. Front. Plant Sci. 11:1008. doi: 10.3389/fpls.2020.01008

Ioannidi, E., Kalamaki, M. S., Engineer, C., Pateraki, I., Alexandrou, D., Mellidou, I., et al. (2009). Expression profiling of ascorbic acid-related genes during tomato fruit development and ripening and in response to stress conditions. J. Exp. Bot. 60, 663-678. doi: 10.1093/jxb/ern322

Ivanov, B. N. (2014). Role of ascorbic acid in photosynthesis. Biochemistry 79, 282-289. doi: 10.1134/S0006297914030146

Ivanov, B., and Khorobrykh, S. (2003). Participation of photosynthetic electron transport in production and scavenging of reactive oxygen species. Antioxid. Redox Signal. 5, 43-53. doi: 10.1089/152308603321223531

Jahns, P., Latowski, D., and Strzalka, K. (2009). Mechanism and regulation of the violaxanthin cycle: the role of antenna proteins and membrane lipids. Biochim. Biophys. Acta 1787, 3-14. doi: 10.1016/j.bbabio.2008.09.013

Jiang, M., and Zhang, J. (2002). Water stress-induced abscisic acid accumulation triggers the increased generation of reactive oxygen species and up-regulates the activities of antioxidant enzymes in maize leaves. J. Exp. Bot. 53, 2401-2410. doi: 10.1093/jxb/erf090

Jung, C. H., and Wells, W. W. (1997). Ascorbic acid is a stimulatory cofactor for mitochondrial glycerol-3-phosphate dehydrogenase. Biochem. Biophys. Res. Commun. 239, 457-462. doi: 10.1006/bbrc.1997.7438

Kärkönen, A., Dewhirst, R. A., Mackay, C. L., and Fry, S. C. (2017). Metabolites of 2,3-diketogulonate delay peroxidase action and induce non-enzymic $\mathrm{H}_{2} \mathrm{O}_{2}$ generation: potential roles in the plant cell wall. Arch. Biochem. Biophys. 620, 12-22. doi: 10.1016/j.abb.2017.03.006

Kawai, Y., Ono, E., and Mizutani, M. (2014). Evolution and diversity of the 2-oxoglutarate-dependent dioxygenase superfamily in plants. Plant J. 78, 328-343. doi: 10.1111/tpj.12479

Khorobrykh, S., Havurinne, V., Mattila, H., and Tyystjärvi, E. (2020). Oxygen and ROS in photosynthesis. Plan. Theory 9:91. doi: 10.3390/plants9010091

Kivirikko, K. I., and Pihlajaniemi, T. (1998). Collagen hydroxylases and the protein disulfide isomerase subunit of prolyl 4-hydroxylases. Adv. Enzymol. Relat. Areas Mol. Biol. 72, 325-398. doi: 10.1002/9780470123188.ch9

Kramarenko, G. G., Hummel, S. G., Martin, S. M., and Buettner, G. R. (2006). Ascorbate reacts with singlet oxygen to produce hydrogen peroxide. Photochem. Photobiol. 82, 1634-1637. doi: 10.1562/2006-01-12-RN-774

Kromdijk, J., Głowacka, K., Leonelli, L., Gabilly, S. T., Iwai, M., Niyogi, K. K., et al. (2016). Improving photosynthesis and crop productivity by accelerating recovery from photoprotection. Science 354, 857-861. doi: 10.1126/science. aai 8878

Kwak, J. M., Mori, I. C., Pei, Z. M., Leonhardt, N., Torres, M. A., Dang, J. L., et al. (2003). NADPH oxidase AtrbohD and AtrbohF genes function in ROS-dependent ABA signaling in Arabidopsis. EMBO J. 22, 2623-2633. doi: 10.1093/emboj/cdg277

Kwon, S. Y., Choi, S. M., Ahn, Y. O., Lee, H. S., Lee, H. B., Park, Y. M., et al. (2003). Enhanced stress-tolerance of transgenic plants expressing a human dehydroascorbate reductase gene. J. Plant Physiol. 160, 347-353. doi: 10.1078/0176-1617-00926

Lange, T. (1994). Purification and partial amino-acid sequence of gibberellin 20-oxidase from Cucurbita maxima L. endosperm. Planta 195, 108-115. doi: $10.1007 /$ BF00206298

Laxa, M., Liebthal, M., Telman, W., Chibani, K., and Dietz, K. J. (2019). The role of the plant antioxidant system in drought tolerance. Antioxidants 8:94. doi: 10.3390/antiox8040094

Le Martret, B., Poage, M., Shiel, K., Nugent, G. D., and Dix, P. J. (2011). Tobacco chloroplast transformants expressing genes encoding dehydroascorbate reductase, glutathione reductase, and glutathione-S-transferase, exhibit altered anti-oxidant metabolism and improved abiotic stress tolerance. Plant Biotechnol. J. 9, 661-673. doi: 10.1111/j.1467-7652.2011.00611.x

Li, H. B., Qin, Y. M., Pang, Y., Song, W. Q., Mei, W. Q., and Zhu, Y. X. (2007). A cotton ascorbate peroxidase is involved in hydrogen peroxide homeostasis during fibre cell development. New Phytol. 175, 462-471. doi: 10.1111/j.1469-8137.2007.02120.x

Li, F., Wu, Q. Y., Sun, Y. L., Wang, L. Y., Yang, X. H., and Meng, Q. W. (2010). Overexpression of chloroplastic monodehydroascorbate reductase enhanced tolerance to temperature and methyl viologen-mediated oxidative stresses. Physiol. Plant. 139, 421-434. doi: 10.1111/j.1399-3054.2010.01369.x

Li, R., Xin, S., Tao, C., Jin, X., and Li, H. (2017). Cotton ascorbate oxidase promotes cell growth in cultured tobacco bright yellow-2 cells through generation of apoplast oxidation. Int. J. Mol. Sci. 18:1346. doi: 10.3390/ ijms 18071346

Lima-Silva, V., Rosado, A., and Amorim-Silva, V. (2012). Genetic and genomewide transcriptomic analyses identify co-regulation of oxidative response and hormone transcript abundance with vitamin $\mathrm{C}$ content in tomato fruit. BMC Genomics 13:187. doi: 10.1186/1471-2164-13-187

Lin, S. T., Chiou, C. W., Chu, Y. L., Hsiao, Y., Tseng, Y. F., Chen, Y. C., et al. (2016). Enhanced ascorbate regeneration via dehydroascorbate reductase confers tolerance to photo-oxidative stress in Chlamydomonas reinhardtii. Plant Cell Physiol. 57, 2104-2121. doi: 10.1093/pcp/pcw129

Lisko, K. A., Torres, R., Harris, R. S., Belisle, M., Vaughan, M. M., Jullian, B., et al. (2013). Elevating vitamin $C$ content via overexpression of myo-inositol oxygenase and 1-gulono-1,4-lactone oxidase in Arabidopsis leads to enhanced biomass and tolerance to abiotic stresses. In Vitro Cell. Dev. Biol. Plant 49, 643-655. doi: 10.1007/s11627-013-9568-y

Liu, Y., Ye, N., Liu, R., Chen, M., and Zhang, J. (2010). $\mathrm{H}_{2} \mathrm{O}_{2}$ mediates the regulation of ABA catabolism and GA biosynthesis in Arabidopsis seed dormancy and germination. J. Exp. Bot. 61, 2979-2990. doi: 10.1093/jxb/ erq125

Ma, L., Wang, Y., Liu, W., and Liu, Z. (2014). Overexpression of an alfalfa GDP-mannose 3, 5-epimerase gene enhances acid, drought and salt tolerance in transgenic Arabidopsis by increasing ascorbate accumulation. Biotechnol. Lett. 36, 2331-2341. doi: 10.1007/s10529-014-1598-y 
Maruta, T., Noshi, M., Tanouchi, A., Tamoi, M., Yabuta, Y., Yoshimura, K., et al. (2012). $\mathrm{H}_{2} \mathrm{O}_{2}$-triggered retrograde signaling from chloroplasts to nucleus plays specific role in response to stress. J. Biol. Chem. 287, 11717-11729. doi: 10.1074/jbc.M111.292847

Maruta, T., Sawa, Y., Shigeoka, S., and Ishikawa, T. (2016). Diversity and evolution of ascorbate peroxidase functions in chloroplasts: more than just a classical antioxidant enzyme? Plant Cell Physiol. 57, 1377-1386. doi: 10.1093/ pcp/pcv203

Minor, E.A., and Court, B.L., Young, J.I and Wang, G. (2013). Ascorbate induces ten-eleven translocation (Tet) methylcytosine dioxygenase-mediated generation of 5-hydroxymethylcytosine. J. Biol. Chem. 288, 13669-13674, doi: 10.1074/ jbc.C113.464800.

Mir, M. A., John, R., Alyemeni, M. N., Alam, P., and Ahmad, P. (2018). Jasmonic acid ameliorates alkaline stress by improving growth performance, ascorbate glutathione cycle and glyoxylase system in maize seedlings. Sci. Rep. 8:2831. doi: 10.1038/s41598-018-21097-3

Mu, P., Conklin, P. P. L., Niyogi, K. K., and Müller-Moulé, P. (2002). Ascorbate deficiency can limit violaxanthin de-epoxidase activity in vivo. Plant Physiol. 128, 970-977. doi: 10.1104/pp.103.032375

Müller-Moulé, P., Golan, T., and Niyogi, K. (2004). Ascorbate deficient mutants of Arabidopsis grow in high light despite chronic photooxidative stress. Plant Physiol. 134, 163-1172. doi: 10.1104/pp.103.032375

Müller-Moulé, P., Havaux, M., and Niyogi, K. K. (2003). Zeaxanthin deficiency enhances the high light sensitivity of an ascorbate-deficient mutant of Arabidopsis. Plant Physiol. 133, 748-760. doi: 10.1104/pp.103.026252

Myllyharju, J. (2003). Prolyl 4-hydroxylases, the key enzymes of collagen biosynthesis. Matrix Biol. 22, 15-24. doi: 10.1016/S0945-053X(03)00006-4

Myllyla, R., Majamaa, K., Günzler, V., Hanauske-Abel, H. M., and Kivirikko, K. I. (1984). Ascorbate is consumed stoichiometrically in the uncoupled reactions catalyzed by prolyl 4-hydroxylase and lysyl hydroxylase. J. Biol. Chem. 259, 5403-5405. doi: 10.1016/S0021-9258(18)91023-9

Nadarajah, K. K. (2020). ROS homeostasis in abiotic stress tolerance in plants. Int. J. Mol. Sci. 21:5208. doi: 10.3390/ijms21155208

Nickle, T. C., and Meinke, D. W. A. (1998). A cytokinesis-defective mutant of Arabidopsis (cyt1) characterized by embryonic lethality, incomplete cell walls, and excessive callose accumulation. Plant J. 15, 321-332. doi: 10.1046/j. 1365-313x.1998.00212.x

Noctor, G., and Foyer, C. H. (1998). Ascorbate and glutathione: keeping active oxygen under control. Annu. Rev. Plant Physiol. Plant Mol. Biol. 49, 249-279. doi: 10.1146/annurev.arplant.49.1.249

Noshi, M., Yamada, H., Hatanaka, R., Tanabe, N., Tamoi, M., and Shigeoka, S. (2017). Arabidopsis dehydroascorbate reductase 1 and 2 modulate redox states of ascorbate-glutathione cycle in the cytosol in response to photooxidative stress. Biosci. Biotechnol. Biochem. 81, 523-533. doi: 10.1080/09168451.2016.1256759

Oliveira, M. F., Geihs, M. A., França, T. F. A., Moreira, D. C., and Hermes-Lima, M. (2018). Is "preparation for oxidative stress" a case of physiological conditioning hormesis? Front. Physiol. 9:945. doi: 10.3389/fphys.2018.00945

Pan, Z., Chen, L., Wang, F., Song, W., Cao, A., Xie, S., et al. (2019). Genomewide identification and expression analysis of the ascorbate oxidase gene family in Gossypium hirsutum reveals the critical role of GhAO1A in delaying dark-induced leaf senescence. Int. J. Mol. Sci. 20:6167. doi: 10.3390/ ijms 20246167

Parsons, H. T., and Fry, S. C. (2012). Oxidation of dehydroascorbic acid and 2,3-diketogulonate under plant apoplastic conditions. Phytochemistry 75, 41-49. doi: 10.1016/j.phytochem.2011.12.005

Pastori, G. M., Kiddle, G., Antoniw, J., Bernard, S., Veljovic-Jovanovic, S., Verrier, P. J., et al. (2003). Leaf vitamin C contents modulate plant defense transcripts and regulate genes controlling development through hormone signaling. Plant Cell 5, 1212-1226. doi: 10.1105/tpc.010538

Pignocchi, C., and Foyer, C. H. (2003). Apoplastic ascorbate metabolism and its role in the regulation of cell signalling. Curr. Opin. Plant Biol. 6, 379-389. doi: 10.1016/S1369-5266(03)00069-4

Pignocchi, C., Kiddle, G., Hernández, I., Foster, S. J., Asensi, A., Taybi, T., et al. (2006). Ascorbate oxidase-dependent changes in the redox state of the apoplast modulate gene transcript accumulation leading to modified hormone signaling and orchestration of defense processes in tobacco. Plant Physiol. 141, 423-435. doi: 10.1104/pp.106.078469

Plumb, W., Townsend, A. J., Rasool, B., Alomrani, S., Razak, N., Karpinska, B., et al. (2018). Ascorbate-mediated regulation of growth, photoprotection, and photoinhibition in Arabidopsis thaliana. J. Exp. Bot. 69, 2823-2835. doi: 10.1093/jxb/ery170

Potters, G., Horemans, N., and Jansen, M. A. K. (2010). The cellular redox state in plant stress biology-a charging concept. Plant Physiol. Biochem. 48, 292-300. doi: 10.1016/j.plaphy.2009.12.007

Prescott, A. G., and John, P. (1996). Dioxygenases: molecular structure and role in plant metabolism. Annu. Rev. Plant Physiol. Plant Mol. Biol. 47, 245-271. doi: 10.1146/annurev.arplant.47.1.245

Qin, A., Shi, Q., and Yu, X. (2011). Ascorbic acid contents in transgenic potato plants overexpressing two dehydroascorbate reductase genes. Mol. Biol. Rep. 38, 1557-1566. doi: 10.1007/s11033-010-0264-2

Qin, H., Wang, Y., Wang, J., Liu, H., Zhao, H., Deng, Z., et al. (2016). Knocking down the expression of GMPase gene OsVTC1-1 decreases salt tolerance of rice at seedling and reproductive stages. PLoS One 11:e0168650. doi: 10.1371/journal.pone.0168650

Qin, X., and Zeevaart, J. A. (1999). The 9-cis-epoxycarotenoid cleavage reaction is the key regulatory step of abscisic acid biosynthesis in water-stressed bean. Proc. Natl. Acad. Sci. U.S.A. 96, 15354-15361. doi: 10.1073/pnas.96. 26.15354

Rahantaniaina, M. S., Li, S., Chatel-Innocenti, G., Tuzet, A., Issakidis-Bourguet, E., Mhamdi, A., et al. (2017). Cytosolic and chloroplastic DHARs cooperate in oxidative stress-driven activation of the salicylic acid pathway. Plant Physiol. 174, 956-971. doi: 10.1104/pp.17.00317

Rodríguez-Rojas, F., Celis-Plá, P. S. M., Méndez, L., Moenne, F., Muñoz, P. T., Lobos, M. G., et al. (2019). MAPK pathway under chronic copper excess in green macroalgae (Chlorophyta): involvement in the regulation of detoxification mechanisms. Int. J. Mol. Sci. 20:4546. doi: 10.3390/ijms20184546

Sadak, M. S., Elhamid, E. M. A., and Mostafa, H. M. (2013). Alleviation of adverse effects of salt stress in wheat cultivars by foliar treatment with antioxidants I. changes in growth, some biochemical aspects and yield quantity and quality. Am. Eurasian J. Agric. Environ. Sci. 13, 1476-1487. doi: 10.5829/idosi.aejaes.2013.13.11.11264

Saga, G., Giorgetti, A., Fufezan, C., Giacometti, G. M., Bassi, R., and Morosinotto, T. (2010). Mutation analysis of violaxanthin de-epoxidase identifies substratebinding sites and residues involved in catalysis. J. Biol. Chem. 285, 23763-23770. doi: $10.1074 /$ jbc.M110.115097

Sahu, M., and Kar, R. K. (2018). Possible interaction of ROS, antioxidants and ABA to survive osmotic stress upon acclimation in Vigna radiata L Wilczek seedlings. Plant Physiol. Biochem. 132, 415-423. doi: 10.1016/j. plaphy.2018.09.034

Sakata, T., Oda, S., Tsunaga, Y., Shomura, H., Kawagishi-Kobayashi, M., Aya, K. et al. (2014). Reduction of gibberellin by low temperature disrupts pollen development in rice. Plant Physiol. 164, 2011-2019. doi: 10.1104/pp.113.234401

Sanmartin, M., Drogoudi, P. A., Lyons, T., Pateraki, I., Barnes, J., and Kanellis, A. K. (2003). Over-expression of ascorbate oxidase in the apoplast of transgenic tobacco results in altered ascorbate and glutathione redox states and increased sensitivity to ozone. Planta 216, 918-928. doi: 10.1007/s00425-002-0944-9

Sanmartin, M., Pateraki, I., Chatzopoulou, F., and Kanellis, A. K. (2007). Differential expression of the ascorbate oxidase multigene family during fruit development and in response to stress. Planta 225, 873-885. doi: 10.1007/s00425-006-0399-5

Sato, Y., Masuta, Y., Saito, K., Murayama, S., and Ozawa, K. (2011). Enhanced chilling tolerance at the booting stage in rice by transgenic overexpression of the ascorbate peroxidase gene, OsAPXa. Plant Cell Rep. 30, 399-406. doi: 10.1007/s00299-010-0985-7

Schieber, M., and Chandel, N. S. (2014). ROS function in redox signaling and oxidative stress. Curr. Biol. 24, R453-R462. doi: 10.1016/j.cub.2014.03.034

Schofield, C. J., and Ratcliffe, P. J. (2004). Oxygen sensing by HIF hydroxylases. Nat. Rev. Mol. Cell Biol. 5, 343-354. doi: 10.1038/nrm1366

Shan, C., Zhang, S., and Ou, X. (2018). The roles of $\mathrm{H}_{2} \mathrm{~S}$ and $\mathrm{H}_{2} \mathrm{O}_{2}$ in regulating AsA-GSH cycle in the leaves of wheat seedlings under drought stress. Protoplasma 255, 1257-1262. doi: 10.1007/s00709-018-1213-5

Shigeoka, S., and Maruta, T. (2014). Cellular redox regulation, signaling, and stress response in plants. Biosci. Biotechnol. Biochem. 78, 1457-1470. doi: 10.1080/09168451.2014.942254

Shikita, M., Fahey, J. W., Golden, T. R., Holtzclaw, W. D., and Talalay, P. (1999). An unusual case of 'uncompetitive activation' by ascorbic acid: purification and kinetic properties of a myrosinase from Raphanus sativus seedlings. Biochem. J. 341, 725-732. doi: 10.1042/bj3410725 
Sierla, M., Rahikainen, M., Salojärvi, J., Kangasjärvi, J., and Kangasjärvi, S. (2013). Apoplastic and chloroplastic redox signaling networks in plant stress responses. Antioxid. Redox Signal. 18, 2220-2239. doi: 10.1089/ars.2012.5016

Smirnoff, N. (2000). Ascorbic acid: metabolism and functions of a multi-facetted molecule. Curr. Opin. Plant Biol. 3, 229-235. doi: 10.1016/ S1369-5266(00)00069-8

Smirnoff, N. (2018). Ascorbic acid metabolism and functions: a comparison of plants and mammals. Free Radic. Biol. Med. 122, 116-129. doi: 10.1016/j. freeradbiomed.2018.03.033

Smirnoff, N., and Wheeler, G. L. (2000). Ascorbic acid in plants: biosynthesis and function. Crit. Rev. Biochem. Mol. Biol. 35, 291-314. doi: 10.1080/10409230008984166

Sofo, A., Scopa, A., Nuzzaci, M., and Vitti, A. (2015). Ascorbate peroxidase and catalase activities and their genetic regulation in plants subjected to drought and salinity stresses. Int. J. Mol. Sci. 16, 13561-13578. doi: 10.3390/ ijms 160613561

Song, M. H., Nair, V. S., and Oh, K. I. (2017). Vitamin C enhances the expression of IL17 in a Jmjd2-dependent manner. BMB Rep. 50, 49-54. doi: 10.5483/BMBRep.2017.50.1.193

Song, T., Zhang, Q., Wang, H., Han, J., Xu, Z., Yan, S., et al. (2018). OsJMJ703, a rice histone demethylase gene, plays key roles in plant development and responds to drought stress. Plant Physiol. Biochem. 132, 183-188. doi: 10.1016/j. plaphy.2018.09.007

Sultana, S., Khew, C. Y., Morshed, M. M., Namasivayam, P., Napis, S., and Ho, C. L. (2012). Overexpression of monodehydroascorbate reductase from a mangrove plant (AeMDHAR) confers salt tolerance on rice. J. Plant Physiol. 169, 311-318. doi: 10.1016/j.jplph.2011.09.004

Sun, W. H., Duan, M., Shu, D. F., Yang, S., and Meng, Q. W. (2010). Overexpression of StAPX in tobacco improves seed germination and increases early seedling tolerance to salinity and osmotic stresses. Plant Cell Rep. 29, 917-926. doi: 10.1007/s00299-010-0878-9

Suzuki, N., and Katano, K. (2018). Coordination between ROS regulatory systems and other pathways under heat stress and pathogen attack. Front. Plant Sci. 9:490. doi: 10.3389/fpls.2018.00490

Szarka, A., Horemans, N., Bánhegyi, G., and Asard, H. (2004). Facilitated glucose and dehydroascorbate transport in plant mitochondria. Arch. Biochem. Biophys. 428, 73-80. doi: 10.1016/j.abb.2004.05.011

Talla, S., Riazunnisa, K., Padmavathi, L., Sunil, B., Rajsheel, P., and Raghavendra, A. S. (2011). Ascorbic acid is a key participant during the interactions between chloroplasts and mitochondria to optimize photosynthesis and protect against photoinhibition. J. Biosci. 36, 163-173. doi: 10.1007/ s12038-011-9000-x

Terzi, R., Kalaycıoglu, E., Demiralay, M., Saglam, A., and Kadioglu, A. (2015). Exogenous ascorbic acid mitigates accumulation of abscisic acid, proline and polyamine under osmotic stress in maize leaves. Acta Physiol. Plant. 37:43. doi: 10.1007/s11738-015-1792-0

Tiainen, P., Myllyharju, J., and Koivunen, P. (2005). Characterization of a second Arabidopsis thaliana prolyl 4-hydroxylase with distinct substrate specificity. J. Biol. Chem. 280, 1142-1148. doi: 10.1074/jbc.M411109200

Triantaphylidès, C., and Havaux, M. (2009). Singlet oxygen in plants: production, detoxification and signaling. Trends Plant Sci. 14, 219-228. doi: 10.1016/j. tplants.2009.01.008

Triantaphylidès, C., Krischke, M., Hoeberichts, F. A., Ksas, B., Gresser, G., Havaux, M., et al. (2008). Singlet oxygen is the major reactive oxygen species involved in photooxidative damage to plants. Plant Physiol. 148, 960-968. doi: 10.1104/pp.108.125690

Tripathi, P., Mishra, A., Dwivedi, S., Chakrabarty, D., Trivedi, P. K., Singh, R. P., et al. (2012). Differential response of oxidative stress and thiol metabolism in contrasting rice genotypes for arsenic tolerance. Ecotoxicol. Environ. Saf. 79, 189-198. doi: 10.1016/j.ecoenv.2011.12.019

Tsukada, Y., Fang, J., Erdjument-Bromage, H., Warren, M. E., Borchers, C. H., Tempst, P., et al. (2006). Histone demethylation by a family of JmjC domaincontaining proteins. Nature 439, 811-816. doi: 10.1038/nature04433

Ushimaru, T., Nakagawa, T., Fujioka, Y., Daicho, K., Naito, M., Yamauchi, Y., et al. (2006). Transgenic Arabidopsis plants expressing the rice dehydroascorbate reductase gene are resistant to salt stress. J. Plant Physiol. 163, 1179-1184. doi: $10.1016 /$ j.jplph.2005.10.002

Veljovic-Jovanovic, S. D., Pignocchi, C., Noctor, G., and Foyer, C. H. (2001). Low ascorbic acid in the vtc-1 mutant of Arabidopsis is associated with decreased growth and intracellular redistribution of the antioxidant system. Plant Physiol. 127, 426-435. doi: 10.1104/pp.010141

Verma, V., Ravindran, P., and Kumar, P. P. (2016). Plant hormone-mediated regulation of stress responses. BMC Plant Biol. 16:86. doi: 10.1186/ s12870-016-0771-y

Vidal-Meireles, A., Tóth, D., Kovács, L., Neupert, J., and Tóth, S. Z. (2020). Ascorbate deficiency does not limit nonphotochemical quenching in Chlamydomonas reinhardtii. Plant Physiol. 182, 597-611. doi: 10.1104/ pp.19.00916

Vlad, F., Spano, T., Vlad, D., Daher, F. B., Ouelhadj, A., Fragkostefanakis, S., et al. (2007). Involvement of Arabidopsis prolyl 4 hydroxylases in hypoxia, anoxia and mechanical wounding. Plant Signal. Behav. 2, 368-369. doi: $10.4161 /$ psb.2.5.4462

Wang, T., Chen, K., Zeng, X., Yang, J., Wu, Y., Shi, X., et al. (2011a). The histone demethylases Jhdm la/lb enhance somatic cell reprogramming in a vitamin-C-dependent manner. Cell Stem Cell 9, 575-587. doi: 10.1016/j. stem.2011.10.005

Wang, F., Cui, X., Sun, Y., and Dong, C. H. (2013). Ethylene signaling and regulation in plant growth and stress responses. Plant Cell Rep. 32, 1099-1109. doi: 10.1007/s00299-013-1421-6

Wang, X. L., Song, S. H., Wu, Y. S., Li, Y. L., Chen, T. T., Huang, Z. Y., et al. (2015). Genome-wide mapping of 5-hydroxymethylcytosine in three rice cultivars reveals its preferential localization in transcriptionally silent transposable element genes. J. Exp. Bot. 66, 6651-6663. doi: 10.1093/jxb/erv372

Wang, J., Wu, B., Yin, H., Fan, Z., Li, X., Ni, S., et al. (2017). Overexpression of $C a A P X$ induces orchestrated reactive oxygen scavenging and enhances cold and heat tolerances in tobacco. Biomed. Res. Int. 2017:4049534. doi: 10.1155/2017/4049534

Wang, Z., Xiao, Y., Chen, W., Tang, K., and Zhang, L. (2010). Increased vitamin $\mathrm{C}$ content accompanied by an enhanced recycling pathway confers oxidative stress tolerance in Arabidopsis. J. Integr. Plant Biol. 52, 400-409. doi: 10.1111/j. 1744-7909.2010.00921.x

Wang, H. S., Yu, C., Zhu, Z. J., and Yu, X. C. (2011b). Overexpression in tobacco of a tomato GMPase gene improves tolerance to both low and high temperature stress by enhancing antioxidation capacity. Plant Cell Rep. 30, 1029-1040. doi: 10.1007/s00299-011-1009-y

Wang, Y., Zhao, H., Qin, H., Li, Z., Liu, H., Wang, J., et al. (2018). The synthesis of ascorbic acid in rice roots plays an important role in the salt tolerance of rice by scavenging ROS. Int. J. Mol. Sci. 19:3347. doi: 10.3390/ ijms 19113347

Waszczak, C., Carmody, M., and Kangasjärvi, J. (2018). Reactive oxygen species in plant signaling. Annu. Rev. Plant Biol. 69, 209-236. doi: 10.1146/annurevarplant-042817-040322

Wu, M., Moon, H. S., Pirskanen, A., Myllyharju, J., Kivirikko, K. I., and Begley, T. P. (2000). Mechanistic studies on prolyl-4-hydroxylase: the vitamin $\mathrm{C}$ requiring uncoupled oxidation. Bioorg. Med. Chem. Lett. 10, 1511-1514. doi: 10.1016/S0960-894X(00)00224-9

Xiang, N., Hu, J., Wen, T., Brennan, M. A., Brennan, C. S., and Guo, X. (2020). Effects of temperature stress on the accumulation of ascorbic acid and folates in sweet corn (Zea mays L.) seedlings. J. Sci. Food Agric. 100, 1694-1701. doi: 10.1002/jsfa.10184

Xu, M., Lu, Y., Yang, H., He, J., Hu, Z., Hu, X., et al. (2015). ZmGRF, a GA regulatory factor from maize, promotes flowering and plant growth in Arabidopsis. Plant Mol. Biol. 87, 157-167. doi: 10.1007/s11103-014-0267-9

Xue, J. H., Chen, G. D., Hao, F., Chen, H., Fang, Z., Chen, F. F., et al. (2019). A vitamin-C-derived DNA modification catalysed by an algal TET homologue. Nature 569, 581-585. doi: 10.1038/s41586-019-1160-0

Yamamoto, A., Bhuiyan, M. N. H., Waditee, R., Tanaka, Y., Esaka, M., Oba, K., et al. (2005). Suppressed expression of the apoplastic ascorbate oxidase gene increases salt tolerance in tobacco and Arabidopsis plants. J. Exp. Bot. 56, 1785-1796. doi: 10.1093/jxb/eri167

Yan, Y., Pan, C., Du, Y., Li, D., and Liu, W. (2018). Exogenous salicylic acid regulates reactive oxygen species metabolism and ascorbate-glutathione cycle in Nitraria tangutorum Bobr. Under salinity stress. Physiol. Mol. Biol. Plants 24, 577-589. doi: 10.1007/s12298-018-0540-5

Yang, D. Y., Ma, N. N., Zhuang, K. Y., Zhu, S. B., Liu, Z. M., and Yang, X. H. (2017). Overexpression of tomato SlGGP-LIKE gene improves tobacco tolerance to methyl viologen-mediated oxidative stress. J. Plant Physiol. 209, 31-41. doi: $10.1016 /$ j.jplph.2016.10.013 
Ye, N., Zhu, G., Liu, Y., Zhang, A., Li, Y., Liu, R., et al. (2012). Ascorbic acid and reactive oxygen species are involved in the inhibition of seed germination by abscisic acid in rice seeds. J. Exp. Bot. 63, 1809-1822. doi: 10.1093/jxb/err336

Yeh, H. L., Lin, T. H., Chen, C. C., Cheng, T. X., Chang, H. Y., and Lee, T. M. (2019). Monodehydroascorbate reductase plays a role in the tolerance of Chlamydomonas reinhardtii to photooxidative stress. Plant Cell Physiol. 60, 2167-2179. doi: 10.1093/pcp/pcz110

Yoshida, S., Tamaoki, M., Shikano, T., Nakajima, N., Ogawa, D., Ioki, M., et al. (2006). Cytosolic dehydroascorbate reductase is important for ozone tolerance in Arabidopsis thaliana. Plant Cell Physiol. 47, 304-308. doi: 10.1093/pcp/pci246

You, J., and Chan, Z. (2015). ROS regulation during abiotic stress responses in crop plants. Front. Plant Sci. 6:1092. doi: 10.3389/fpls.2015.01092

Young, J. I., Züchner, S., and Wang, G. (2015). Regulation of the epigenome by vitamin C. Annu. Rev. Nutr. 35, 545-564. doi: 10.1146/annurevnutr-071714-034228

Yu, Y., Wang, J., Li, S., Kakan, X., Zhou, Y., Miao, Y., et al. (2019). Ascorbic acid integrates the antagonistic modulation of ethylene and abscisic acid in the accumulation of reactive oxygen species. Plant Physiol. 179, 1861-1875. doi: $10.1104 /$ pp.18.01250

Zechmann, B. (2018). Compartment-specific importance of ascorbate during environmental stress in plants. Antioxid. Redox Signal. 29, 1488-1501. doi: 10.1089/ars.2017.7232

Zhang, C. J., and Guo, Y. (2012). OsTRXh1 regulates the redox state of the apoplast and influences stress responses in rice. Plant Signal. Behav. 7, 440-442. doi: 10.4161/psb.19244
Zhang, T., Huang, K., Zhu, Y., Wang, T., Shan, Y., Long, B., et al. (2019). Vitamin C-dependent lysine demethylase 6 (KDM6)-mediated demethylation promotes a chromatin state that supports the endothelialto-hematopoietic transition. J. Biol. Chem. 294, 13657-13670. doi: 10.1074/ jbc.RA119.009757

Zhang, Z., Wang, J., Zhang, R., and Huang, R. (2012). The ethylene response factor AtERF98 enhances tolerance to salt through the transcriptional activation of ascorbic acid synthesis in Arabidopsis. Plant J. 71, 273-287. doi: 10.1111/j. 1365-313X.2012.04996.X

Zhang, H., Xiang, Y., He, N., Liu, X., Liu, H., Fang, L., et al. (2020). Enhanced vitamin $\mathrm{C}$ production mediated by an ABA-induced PTP-like nucleotidase improves drought tolerance of Arabidopsis and maize. Mol. Plant 13, 760-776. doi: 10.1016/j.molp.2020.02.005

Conflict of Interest: The authors declare that the research was conducted in the absence of any commercial or financial relationships that could be construed as a potential conflict of interest.

Copyright (c) 2021 Xiao, Li, Zhu, Wang, Zhang, Zheng, Zhao, Zhang, Wang and Zhang. This is an open-access article distributed under the terms of the Creative Commons Attribution License (CC BY). The use, distribution or reproduction in other forums is permitted, provided the original author(s) and the copyright owner(s) are credited and that the original publication in this journal is cited, in accordance with accepted academic practice. No use, distribution or reproduction is permitted which does not comply with these terms. 